\title{
Ultrasonographic measurement of the vascular wall thickness and intima-media thickness in patients with Behçet's disease with symptoms or signs of vascular involvement: A cross-sectional study
}

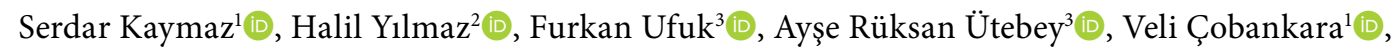

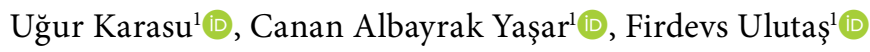 \\ ${ }^{1}$ Department of Internal Medicine, Division of Rheumatology, Pamukkale University Faculty of Medicine, Denizli, Turkey \\ ${ }^{2}$ Department of Gastroenterology, Pamukkale University Faculty of Medicine, Denizli, Turkey \\ ${ }^{3}$ Department of Radiology, Pamukkale University Faculty of Medicine, Denizli, Turkey
}

\begin{abstract}
Objectives: This study aims to measure and compare bilateral carotid intima-media thickness (CIMT), bilateral jugular, common femoral, and main portal vein wall thicknesses (VWTs) in Behçet's disease (BD) patients with and without vascular involvement to obtain a cut-off value for vascular complications and determine their relationship with disease activity.

Patients and methods: Sixty-three BD patients (41 males, 22 females; median age: 38.0 years; min 20 - max 71 years) and 30 healthy control subjects (14 males, 16 females; median age: 40.3 years; $\min 21$ - max 60 years) were included in this cross-sectional study between February and March 2020. According to imaging findings, BD patients were divided into two groups as those with and without vascular complications. Disease duration, medical treatment and BD manifestations of patients were questioned. Disease activity was evaluated using the Behçet's Disease Current Activity Form (BDCAF) and the Behçet's Syndrome Activity Scale (BSAS). Two radiologists blinded to the diagnosis of BD used ultrasound to measure VWT and CIMT. Receiver operating characteristics were assessed to obtain sensitivity and specificity values for each VWT and CIMT.

Results: The groups were similar in terms of age, sex, and body mass index $(p>0.05)$. There was a significant difference between the BD groups when the BDCAF and BSAS scores were compared, while there was no difference between them in terms of disease duration and medical treatment $(p>0.05)$. All VWTs and CIMTs were significantly higher in patients with BD compared to healthy controls $(p<0.05)$. There was no significant difference between the BD groups in terms of CIMT, jugular and common femoral VWTs ( $p>0.05$ ). But portal VWT was significantly higher in patients with vascular involvement $(p<0.05)$. A cut-off value of $\geq 1.35 \mathrm{~mm}$ yielded a sensitivity of $79.2 \%$ and a specificity of $82.4 \%$ for the diagnosis of vascular involvement with the highest Youden's index (area under the curve, $0.869 ; 95 \%$ confidence interval, 0.783 to 0.956 ).

Conclusion: Portal VWT has high sensitivity and specificity for the screening of vascular involvement in patients with BD.

Keywords: Behçet's disease, carotid intima-media thickness, ultrasound, vascular involvement, venous thrombosis.
\end{abstract}

Behçet's disease (BD) is a multi-systemic inflammatory syndrome, which is classified as variable vessel vasculitis according to the Chapel Hill classification and leads to arterial and venous involvement. ${ }^{1}$ Vascular involvement may occur in $40 \%$ of BD patients. Venous wall inflammation presents with deep vein thrombosis and superficial thrombophlebitis, while arterial wall inflammation presents with thrombosis and aneurysm. ${ }^{2,3}$ Although lower extremity venous thrombosis is the most common type of involvement, cardiac involvements can also be seen with the superior

Received: August 24, 2020 Accepted: September 28, 2020 Published online: January 14, 2021

Correspondence: Serdar Kaymaz, MD. Pamukkale Üniversitesi Tıp Fakültesi İç Hastalıkları Anabilim Dalı, Romatoloji Bilim Dalı, 20070 Kınıkı, Denizli, Türkiye. Tel: +90553-8720626 e-mail: dr.serdarkymaz@gmail.com

Citation:

Kaymaz S, Yılmaz H, Ufuk F, Ütebey AR, Çobankara V, Karasu U, et al. Ultrasonographic measurement of the vascular wall thickness and intima-media thickness in patients with Behçet's disease with symptoms or signs of vascular involvement: A cross-sectional study. Arch Rheumatol 2021;36(2):258-266. 
and inferior vena cava, pulmonary artery, portal vein, and suprahepatic veins. ${ }^{4,5}$

There is no reliable assessment tool to identify vascular wall inflammation in $\mathrm{BD}$, except for detecting ongoing intravascular thrombosis with ultrasonography (US). Previous studies investigated arterial vessel wall thickness with US (mostly in carotid arteries) in BD. In a recent meta-analysis of nine studies assessing endothelial dysfunction with flow-mediated dilation (FMD) and intima-media thickness (IMT) of the arterial wall, FMD was found to be impaired in BD even in inactive disease, suggesting a low-level chronic inflammation. ${ }^{6}$ However, the number of studies evaluating VWT is limited in the literature. VWT is an important marker for venous diseases. This has been reported to be related to venous insufficiency and hypertension due to thrombosis caused by inflammation. ${ }^{7}$ However, Alibaz-Oner et al., 8 stated that venous insufficiency may be present in BD patients, even if there is no history of thrombosis. A study conducted in the United Kingdom found increased popliteal vein wall thickness (VWT) in BD patients though there was no history of thrombosis. ${ }^{9}$ In another study, it was stated that lower extremity VWT was increased in BD patients independently of vascular activity and important in the diagnosis. ${ }^{10}$ However, studies in the literature evaluated only lower extremity VWTs, whereas the relationship of VWT with disease activity has not been emphasized. In this study, we aimed to measure and compare bilateral carotid IMT (CIMT), bilateral jugular, common femoral, and main portal VWTs in BD patients with and without vascular involvement to obtain a cut-off value for vascular complications and determine their relationship with disease activity.

\section{PATIENTS AND METHODS}

This cross-sectional study evaluated 64 patients with BD classified by the Assessment in International Criteria for Behçet's Disease and excluded one patient due to cirrhosis. Therefore, the study included $63 \mathrm{BD}$ patients (41 males, 22 females; median age: 38.0 years; min 20 - max 71 years) and 30 healthy controls (14 males, 16 females; median age: 40.3 years; min 21 - max 60 years). ${ }^{11}$ The study enrolled patients from the Department of Rheumatology of Pamukkale University
Faculty of Medicine, and healthy controls who were blood donors from the blood bank of the institution or who were university personnel and family members between February and March 2020. The study protocol was approved by the Pamukkale University Clinical Research Ethics Committee (Approval no: 60116787-020/18936). A written informed consent was obtained from each participant. The study was conducted in accordance with the principles of the Declaration of Helsinki.

The healthy controls filled in a questionnaire involving questions about smoking status and demographic data such as sex and age. The body mass indexes (BMIs) of the healthy controls and the $\mathrm{BD}$ patients were measured. The duration of diagnosis, medical treatments, and smoking status were recorded in the $\mathrm{BD}$ patients. The $\mathrm{BD}$ patients were asked to fill in the Behçet's Disease Current Activity Form (BDCAF) and the Behçet's Syndrome Activity Scale (BSAS). ${ }^{12,13}$ A detailed anamnesis was taken from the $\mathrm{BD}$ patients and their physical examinations were performed. In addition, their laboratory results and imaging findings were evaluated. Doppler US, contrast-enhanced computed tomography (CT) or CT, CT- or magnetic resonance imaging (MRI)-angiography and echocardiography examinations, which were ordered with the pre-diagnosis of vascular involvement, were carefully examined. In the literature, vascular involvement patterns have been determined in BD patients. ${ }^{14,15}$ Routine laboratory tests for all patients and healthy controls, including complete blood count, fasting plasma glucose, and liver and renal function tests, were also evaluated.

All US examinations were performed by an aboard-certified radiologist with seven years of experience in US imaging who was blinded to cases on the same day with clinical assessment. A second radiologist with an experience of three years in US imaging performed IMT and VWT measurements of the first 20 individuals on the same day with the first radiologist to evaluate the inter-observer agreement. All US examinations were performed after a fasting period of $6 \mathrm{~h}$. Bilateral CIMT, jugular vein, and common femoral VWTs were measured using a 4-15-MHz ML6-15 linear transducer (Logiq E9, General Electric Company, Fairfield, CT, USA). 
mesenteric, The portal vein, inferior vena cava, superior renal, and splenic VWTs were measured using a 2-8-MHz 9L-D linear transducer (Logiq E9, General Electric Company, Fairfield, CT, USA). US examinations were performed with a high-resolution US system (LOGIQ E9; GE Healthcare, Wauwatosa, WI, USA). VWTs were evaluated during the Valsalva maneuver and IMT was measured during neutral breathing in the supine position. All veins were evaluated in both longitudinal and transverse planes. CIMT was automatically measured in a longitudinal axis using the Auto-IMT application (GE Healthcare, Wauwatosa, WI, USA). Three measurements were performed by the observers from each vessel and the average of these measurements for each vessel was noted (Figures 1-3).

\section{Statistical analysis}

Statistical analysis was performed using the IBM SPSS version 22.0 software (IBM Corp., Armonk, NY, USA). Based on the data obtained from other studies, it was found that a sample size of 25 patients for each group would provide 85\% power or above when determining the significance of the differences in clinical parameters and whether or not the patients with $\mathrm{BD}$ had vascular involvement. Demographic characteristics were described by using descriptive statistics. The Kolmogorov-Smirnov test was used to test the normality of the data. Non-parametric tests were used in statistical analyses when the data were non-normally distributed. The significance of the differences for continuous variables was analyzed by the Kruskal-Wallis variance analysis, while the Chi-square test was used to analyze categorical variables at baseline. The correlation between nonparametric variables was evaluated by Spearman's correlation analysis. A correlation coefficient $(r)$ of $<0.2$ was considered as negligible, 0.2 to 0.4 as fair, 0.41 to 0.60 as moderate, 0.61 to 0.80 as good, and $>0.8$ as excellent agreement. In the intergroup comparisons, the post hoc Bonferroni correction (Mann-Whitney $\mathrm{U}$ test) and the Kruskal-Wallis variance analysis were used. For each VWT, the sensitivity and specificity were computed and graphed in a receiver operating characteristic (ROC) curve according to the diagnosis of vascular involvement. The ROC curve was used to select optimal cut-off VWT scores for screening patients who had vascular involvement. In addition, the

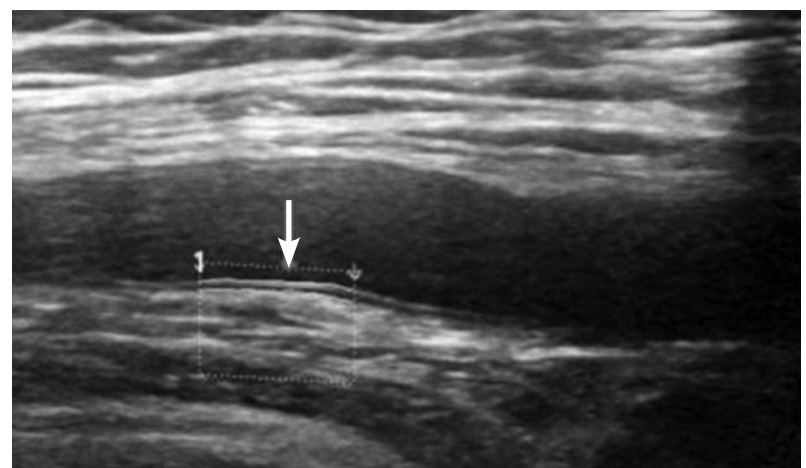

Figure 1. Brightness-mode ultrasound image of carotid artery in longitudinal plane showing posterior intima-media thickness measurement in a healthy control (arrow).

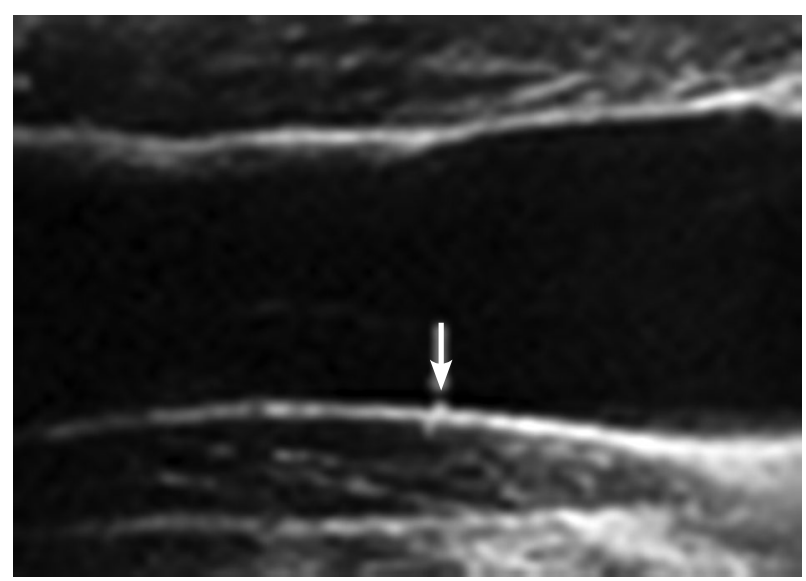

Figure 2. Brightness-mode ultrasound image of jugular vein in longitudinal plane showing vein wall thickness measurement in a healthy control (arrow).

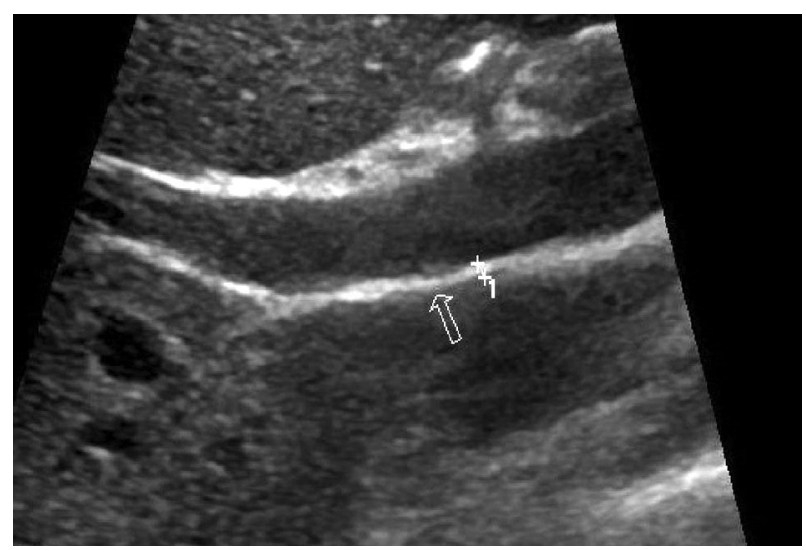

Figure 3. Brightness-mode ultrasound image of portal vein in longitudinal plane showing vein wall thickness measurement in a healthy control (arrow). 
discriminative statistics of sensitivity, specificity, positive, and negative predictive values were assessed. A $p$ value of $<0.0167$ was considered statistically significant in the post hoc Bonferroni correction analysis, while a $p$ value of $<0.05$ was considered statistically significant in all other analyses.

\section{RESULTS}

After a detailed examination, BD patients were divided into two groups as those with and without vascular involvement. Twenty-five of the BD patients with vascular involvement were enrolled in Group 1, while 38 without vascular involvement were enrolled in Group 2.

There was no statistically significant difference between Group 1 and Group 2 in terms of medical treatment, BD manifestations, and disease duration; however, there were statistically significant differences between the two groups in terms of BSAS and BDCAF scores $(p<0.05)$ (Table 1). In Group 1, 15 (60\%) patients had deep vein thrombosis, one (4\%) patient had hepatic vein thrombosis, two (8\%) patients had cerebral sinus thrombosis, one (4\%) patient had retinal vein occlusion, one (4\%) patient had pulmonary artery aneurysm, one (4\%) patient had pulmonary embolism, one (4\%) patient had iliac vein thrombosis, one (4\%) patient had jugular vein thrombosis, and two (8\%) patients had thrombophlebitis (Table 1).

The inter-observer agreement was fair to moderate for the measurement of VWTs of the inferior vena cava, superior mesenteric vein, splenic vein, and renal vein ( $\mathrm{r}$ values were 0.505 , $0.513,0.382$ and 0.514 , respectively). Therefore, these vessels were excluded from further analysis. There was a good correlation between the radiologists in terms of the mean jugular, main portal, mean common femoral VWTs ( $r$ values

Table 1. Comparison of clinical characteristics of Behçet's disease patients with and without vascular involvement

\begin{tabular}{|c|c|c|c|c|c|c|c|c|c|}
\hline & \multicolumn{4}{|c|}{$\begin{array}{c}\text { Group } 1(\mathrm{n}=25) \\
\text { BD with vascular involvement }\end{array}$} & \multicolumn{4}{|c|}{$\begin{array}{c}\text { Group } 2(\mathrm{n}=38) \\
\text { BD without vascular involvement }\end{array}$} & \multirow[b]{2}{*}{$p$} \\
\hline & $\mathrm{n}$ & $\%$ & Median & IQR & $\mathrm{n}$ & $\%$ & Median & IQR & \\
\hline Disease duration (year) & & & 9 & 6 & & & 9 & 5 & 0.997 \\
\hline $\begin{array}{l}\text { Medical treatment } \\
\text { Colchicum } \\
\text { Nonbiologic immunosuppressive agents } \\
\text { Interferon } \\
\text { Anti-tumor necrosis factors } \\
\text { Anticoagulant }\end{array}$ & $\begin{array}{c}11 \\
7 \\
3 \\
6 \\
10\end{array}$ & $\begin{array}{l}46 \\
29 \\
12 \\
25 \\
42\end{array}$ & & & $\begin{array}{l}20 \\
14 \\
5 \\
4 \\
-\end{array}$ & $\begin{array}{l}53 \\
37 \\
13 \\
11 \\
-\end{array}$ & & & 0.609 \\
\hline $\begin{array}{l}\text { Behçet's disease manifestations } \\
\text { Mucocutaneous } \\
\text { Ocular+mucocutaneous } \\
\text { Neurologic+mucocutaneous } \\
\text { Joints+mucocutaneous }\end{array}$ & $\begin{array}{c}10 \\
9 \\
2 \\
3\end{array}$ & $\begin{array}{c}42 \\
38 \\
8 \\
12\end{array}$ & & & $\begin{array}{r}13 \\
19 \\
3 \\
3\end{array}$ & $\begin{array}{c}34 \\
50 \\
8 \\
8\end{array}$ & & & 0.145 \\
\hline $\begin{array}{l}\text { Clinical characteristics of patients with vascular } \\
\text { involvement } \\
\text { Deep vein thrombosis } \\
\text { Hepatic vein thrombosis } \\
\text { Cerebral sinus vein thrombosis } \\
\text { Retinal vein occlusion } \\
\text { Pulmonary artery aneurysm } \\
\text { Pulmonary embolism } \\
\text { Iliac vein thrombosis } \\
\text { Jugular vein thrombosis } \\
\text { Thrombophlebitis }\end{array}$ & $\begin{array}{c}15 \\
1 \\
2 \\
1 \\
1 \\
1 \\
1 \\
1 \\
2\end{array}$ & $\begin{array}{c}60 \\
4 \\
8 \\
4 \\
4 \\
4 \\
4 \\
4 \\
8\end{array}$ & & & $\begin{array}{l}- \\
- \\
- \\
- \\
- \\
- \\
- \\
- \\
-\end{array}$ & $\begin{array}{l}- \\
- \\
- \\
- \\
- \\
- \\
- \\
- \\
-\end{array}$ & & & - \\
\hline BDCAF & & & 2 & 1.5 & & & 1.5 & 1 & $<0.001^{*}$ \\
\hline BSAS & & & 23.5 & 17 & & & 17.5 & 10 & $0.004^{*}$ \\
\hline
\end{tabular}

BD: Behçet's Disease; IQR: Interquartile range; BDCAF: Behçet's disease Current Activity Form; BSAS: Behçet's Syndrome Activity Scale; Mann-Whitney U test was used. * $p<0.05$ : Statistically significant. 


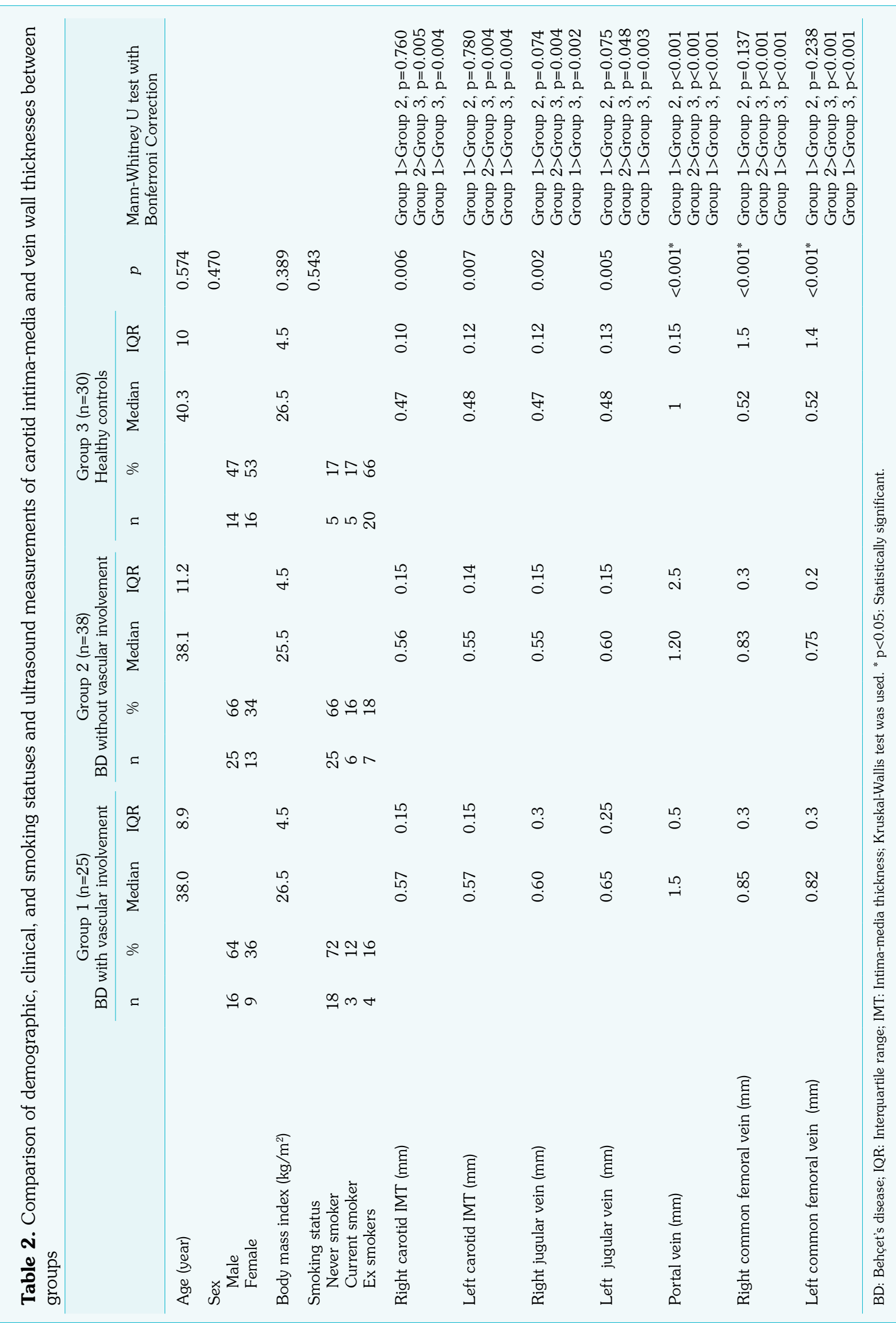


Table 3. Correlation of carotid intima-media and vein wall thicknesses with disease activity

\begin{tabular}{|c|c|c|c|c|c|c|c|c|}
\hline & \multicolumn{2}{|c|}{ Carotid IMT } & \multicolumn{2}{|c|}{ Jugular vein thickness } & \multicolumn{2}{|c|}{ Portal vein thickness } & \multicolumn{2}{|c|}{ Common femoral vein thickness } \\
\hline & $\mathrm{r}$ & $p$ & $\mathrm{r}$ & $p$ & $\mathrm{r}$ & $p$ & $\mathrm{r}$ & $p$ \\
\hline BDCAF & 0.021 & 0.868 & 0.031 & 0.862 & 0.145 & 0.260 & 0.179 & 0.165 \\
\hline BSAS & 0.045 & 0.726 & 0.082 & 0.526 & 0.121 & 0.350 & 0.248 & 0.052 \\
\hline
\end{tabular}

IMT: Intima-media thickness; BDCAF: Behçet's Disease Current Activity Form; BSAS: Behçet's Syndrome Activity Scale; All values are Spearman's correlation coefficients (95\% confidence intervals); $\mathrm{p}<0.05$ : Statistically significant.

Table 4. Diagnostic performance of vein wall thickness measurements in Behçet's disease

\begin{tabular}{|c|c|c|c|c|c|c|}
\hline Vein wall thickness measurements & AUC 95\% CI & Cut-off (mm) & Sensitivity & Specificity & $\begin{array}{c}\text { Positive } \\
\text { predictive value }\end{array}$ & $\begin{array}{c}\text { Negative } \\
\text { predictive value }\end{array}$ \\
\hline $\begin{array}{l}\text { Right common femoral VWT } \\
\text { measurements }\end{array}$ & 0.706 & 0.75 & 66.7 & 56.9 & 20.6 & 95.2 \\
\hline $\begin{array}{l}\text { Left common femoral VWT } \\
\text { measurements }\end{array}$ & 0.680 & 0.65 & 70.8 & 57.4 & 18.9 & 94.55 \\
\hline Portal VWT measurements & 0.869 & 1.35 & 79.2 & 82.4 & 31.8 & 97.14 \\
\hline Right jugular VWT measurements & 0.681 & 0.55 & 66.7 & 66.2 & 16.6 & 94.0 \\
\hline Left jugular VWT measurements & 0.659 & 0.75 & 70.8 & 57.4 & 20.69 & 95.2 \\
\hline
\end{tabular}

were $0.889,0.807,0.884$, respectively, and $\mathrm{p}<0.001$ for all) and CIMT values $(r=0.876$, $\mathrm{p}<0.001$ ).

There was no statistically significant difference between the three groups in terms of age, smoking status, sex distribution, and BMI ( $p>0.05)$. However, there were statistically significant differences in terms of CIMT, and jugular, portal, and common femoral VWTs $(p<0.05)$ (Table 2). The intergroup comparison showed that Group 1 had statistically significantly thicker portal VWT than Group 2 and healthy controls $(p<0.001)$. However, there were no significant differences between Group 1 and Group 2 in terms of bilateral CIMT, jugular, and common femoral VWTs ( $p>0.05)$ (Table 2). There was no relationship or correlation between the VWT and CIMT and the mean scores of BDCAF and BSAS ( $>00.05)$ (Table 3).

The diagnostic performance of VWT for vascular involvement in $\mathrm{BD}$ patients was evaluated by ROC analysis. When the cut-off value was taken as $1.35 \mathrm{~mm}$ for portal VWT, the sensitivity and specificity for vascular involvement were $79.2 \%$ and $82.4 \%$, respectively (area under the curve $[\mathrm{AUC}]=0.869,95 \%$ confidence interval $[\mathrm{CI}]$, 0.783-0.956) (Table 4, Figure 4). When the cut-off value was taken as $0.75 \mathrm{~mm}$ for the right common

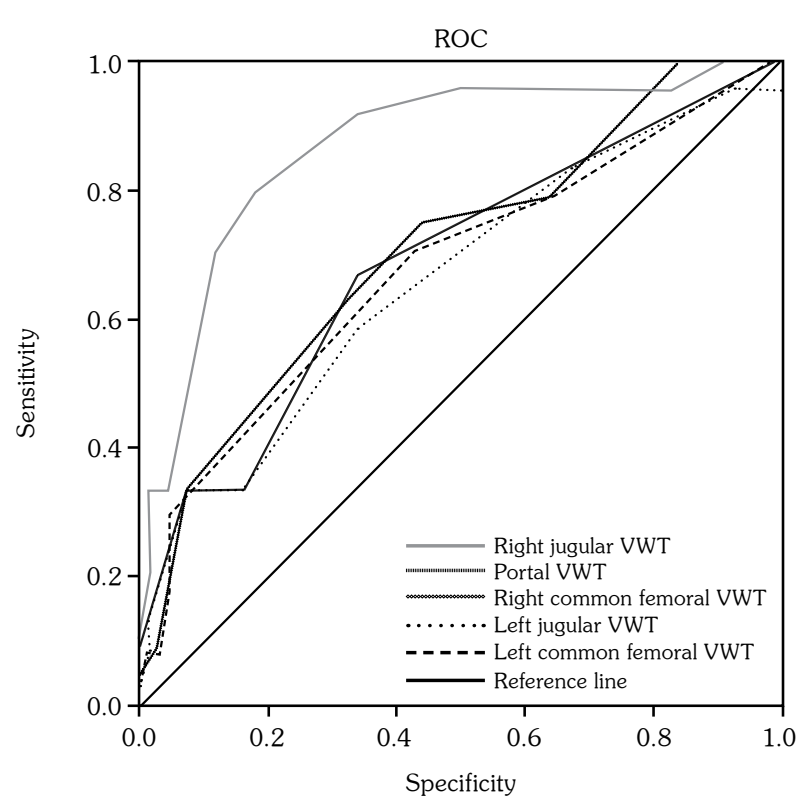

Figure 4. Receiver operating characteristic curve for vein wall and carotid intima-media thicknesses.

ROC: Receiver operating characteristic; VWT: Vein wall thickness. 
femoral vein, the sensitivity and specificity were $66.7 \%$ and $56.9 \%$, respectively (AUC $=0.706$, $95 \%$ CI, 0.583 to 0.829 ) (Table 4, Figure 4). The sensitivity and specificity of the VWTs and their predictive values are shown in Table 4.

\section{DISCUSSION}

It was observed in our study that VWTs and CIMT other than the portal vein were similar in BD patients with and without vascular involvement. The sensitivity and specificity of portal VWT for determining venous complications were higher than those of other VWTs and CIMT. However, these had no relationship or correlation with disease activity.

In the literature, there are studies emphasizing the significance of CIMT in BD patients. A study by Messedi et al. ${ }^{16}$ stated that CIMT was affected independently of disease manifestations, disease duration, or corticoid therapy in BD patients, which might be related to subclinical atherosclerotic changes. In addition, three studies showed that CIMT was not affected by disease activation or clinical condition in BD patients. ${ }^{6,17,18}$ Our study also revealed that CIMT was not affected by vascular involvement and disease activity, and was significantly higher in $\mathrm{BD}$ patients compared to the healthy control group. Increased CIMT indicates the presence of subclinical atherosclerotic changes in BD patients.

There are very limited data assessing VWT in BD. A study by Ambrose et al. ${ }^{9}$ evaluating the popliteal VWT in BD patients with MRI demonstrated that the wall thickness of $\mathrm{BD}$ patients was increased compared to healthy controls. Boulon et al. ${ }^{19}$ evaluated the saphenous VWT with Doppler US in BD patients without a history of thrombosis. As a result of the study, VWT was shown to be increased compared to healthy controls. In our study, we also found that the jugular, portal, and common femoral VWTs were significantly higher in BD patients without vascular involvement compared to healthy controls. In the literature, the most widely accepted reason for the increase in VWT compared to healthy controls, though there is no vascular complication, was explained by a systemic inflammation or increased blood flow to the inflammation site. ${ }^{9}$ However, the number of studies on the pathophysiology of systemic inflammation is limited. Tong et al. ${ }^{20}$ stated that chemokines and cytokines such as interleukin-8, tumor necrosis factor-alpha, interferon-gamma, granulocyte-macrophage colony-stimulating factor (GM-CSF)/G-CSF and CXCL-8, which were found in high levels in $\mathrm{BD}$ patients, caused neutrophil and lymphocyte infiltration in vascular structures. There is also a study stating that reactive oxygen radicals produced by nicotinamide adenine dinucleotide phosphate oxidase cause changes in the wall structure. ${ }^{21}$ This may explain why VWT is thicker in BD patients without vascular involvement compared to healthy controls.

In BD patients, vascular involvement leads to serious complications, increasing morbidity and mortality. Therefore, early diagnosis and aggressive treatment are of critical importance in the management of patients. ${ }^{22}$ Although US, computed tomography, MRI-venography, and angiography are used for the diagnosis of vascular involvement in BD patients, we could not find an appropriate imaging recommendation in the literature for its screening. ${ }^{23}$ However, Doppler US is a practical, easy-to-access, cost-effective and non-ionizing examination with increasing use in rheumatology clinics in recent years. ${ }^{10}$ In a study by Alibaz-Oner et al., ${ }^{10}$ when the lower extremity VWTs were evaluated with Doppler US, it was emphasized that a cut-off value of $0.49 \mathrm{~mm}$ obtained for common femoral vein was highly sensitive and specific to differentiate $\mathrm{BD}$ from vasculitis and spondyloarthropathies. In another study, the sensitivity and specificity were determined as $72 \%$ and $90 \%$, respectively, when the cut-off value was taken as $>0.617 \mathrm{~mm}$ for the common femoral vein evaluated by a similar method. ${ }^{22}$ Furthermore, both studies showed that lower extremity VWTs were not statistically different between BD patients with and without vascular involvement. ${ }^{10,22}$ Similarly, in our study, there was no statistical difference between those with and without vascular involvement in terms of bilateral jugular, common femoral VWTs, and CIMT. However, the cut-off value and the sensitivity and specificity values obtained for the common femoral vein, which was commonly evaluated in all three studies, were different among the studies. This can be explained by different reasons. The first and perhaps the most important reason is the sample difference. 
The study by Alibaz-Oner et al. ${ }^{10}$ employed male $\mathrm{BD}$ patients only, while another study showed sex to affect vascular wall thickness. ${ }^{24}$ Another important reason is that US is an operator-dependent technique. There are studies indicating that this is a major limitation of US. ${ }^{25}$

Early recognition of vascular involvement improves morbidity and mortality in $\mathrm{BD} .^{2}$ In our study, it was found that portal VWT was significantly higher in BD patients with vascular involvement compared to those without vascular involvement, and its sensitivity and specificity for the diagnosis of vascular involvement were 79\% and $82 \%$, respectively, when the cut-off value was taken as $1.35 \mathrm{~mm}$. The cut-off value obtained may be a guide for screening vasculo-BD. However, there is a need for large-scale prospective studies to verify this result.

In the literature, there are scales that evaluate the activation of BD. ${ }^{12,13}$ In our study, no correlation was found between wall thickness and the scales. This may be related to the fact that the scales examine other organ involvements rather than vascular activation. In a study by Buzatu et al., ${ }^{26}$ it was stated that the Birmingham Vasculitis Activity Score, which evaluates vascular activation in BD patients, was more sensitive than BDCAF. Therefore, not evaluating vascular activation with a scale that evaluates vascular activation in BD patients is a limitation of our study. This study's cross-sectional design is another important limitation. It would be possible to conduct a prospective study to understand whether the values we obtained remained stable throughout the vascular complication or whether they were affected by the treatment administered. In addition, $60 \%$ of the patients with vascular involvement had lower extremity venous involvement in our study. If there were more vascular complications in different anatomical regions, our cut-off value could be different or more valuable.

In conclusion, portal VWT was higher in BD patients with vascular involvement compared to those without vascular involvement and healthy controls. Our results suggest that portal VWT measurement with US, a non-invasive radiological imaging modality, might be used as a screening tool for vasculo-BD with sensitivity and specificity values higher than $75 \%$ for the cut-off value $\geq 1.35 \mathrm{~mm}$.

\section{Declaration of conflicting interests}

The authors declared no conflicts of interest with respect to the authorship and/or publication of this article.

\section{Funding}

The authors received no financial support for the research and/or authorship of this article.

\section{REFERENCES}

1. Jennette JC, Falk RJ, Bacon PA, Basu N, Cid MC, Ferrario F, et al. 2012 revised International Chapel Hill Consensus Conference Nomenclature of Vasculitides. Arthritis Rheum 2013;65:1-11.

2. Calamia KT, Schirmer M, Melikoglu M. Major vessel involvement in Behçet's disease: an update. Curr Opin Rheumatol 2011;23:24-31.

3. Yazici H, Yurdakul S, Hamuryudan V. Behçet disease. Curr Opin Rheumatol 2001;13:18-22.

4. Kural-Seyahi E, Fresko I, Seyahi N, Ozyazgan Y, Mat $\mathrm{C}$, Hamuryudan V, et al. The long-term mortality and morbidity of Behçet syndrome: a 2-decade outcome survey of 387 patients followed at a dedicated center. Medicine (Baltimore) 2003;82:60-76.

5. Ufuk F. Inferior Vena Cava Thrombosis in Behçet Disease. Radiology 2019;292:288.

6. Merashli M, Ster IC, Ames PR. Subclinical atherosclerosis in Behcet's disease: A systematic review and meta-analysis. Semin Arthritis Rheum 2016;45:502-10.

7. Labropoulos N, Summers KL, Sanchez IE, Raffetto $J$. Saphenous vein wall thickness in age and venous reflux-associated remodeling in adults. J Vasc Surg Venous Lymphat Disord 2017;5:216-23.

8. Alibaz-Oner F, Karatay E, Akpinar IN, Ergun T, Direskeneli $\mathrm{H}$. Evaluation of asymptomatic venous disease by venous Doppler ultrasonography in patients with Behcet's disease without overt thrombosis. Clin Rheumatol 2014;33:277-80.

9. Ambrose N, Pierce IT, Gatehouse PD, Haskard DO, Firmin DN. Magnetic resonance imaging of vein wall thickness in patients with Behçet's syndrome. Clin Exp Rheumatol 2014;32(4 Suppl 84):S99-102.

10. Alibaz-Oner F, Ergelen R, Mutis A, Erturk Z, Asadov $\mathrm{R}$, Mumcu $\mathrm{G}$, et al. Venous vessel wall thickness in lower extremity is increased in male patients with Behcet's disease. Clin Rheumatol 2019;38:1447-51.

11. Davatchi F, Sadeghi Abdollahi B, Chams-Davatchi C, Shahram F, Shams H, Nadji A, et al. The saga of diagnostic/classification criteria in Behcet's disease. Int $J$ Rheum Dis 2015;18:594-605.

12. Hatemi G, Merkel PA, Hamuryudan V, Boers M, Direskeneli H, Aydin SZ, et al. Outcome measures used in clinical trials for Behçet syndrome: a systematic review. J Rheumatol 2014;41:599-612. 
13. Lawton G, Bhakta BB, Chamberlain MA, Tennant A. The Behcet's disease activity index. Rheumatology (Oxford) 2004;43:73-8.

14. Calamia KT, Schirmer M, Melikoglu M. Major vessel involvement in Behçet disease. Curr Opin Rheumatol 2005; 17:1-8.

15. Fei Y, Li X, Lin S, Song X, Wu Q, Zhu Y, et al. Major vascular involvement in Behçet's disease: a retrospective study of 796 patients. Clin Rheumatol 2013;32:845-52.

16. Messedi M, Frigui M, Ben Mahfoudh K, Feki H, Ben Mahfoudh ST, Mnif J, et al. Intima-media thickness of carotid artery in patients with Behçet's disease. Arch Med Res 2011;42:398-404.

17. Oztürk MA, Oktar SO, Unverdi S, Ureten K, Göker $\mathrm{B}$, Haznedaroglu S, et al. Morphologic evidence of subclinical atherosclerosis obtained by carotid ultrasonography in patients with Behcet's disease. Rheumatol Int 2006;26:867-72.

18. Hong SN, Park JC, Yoon NS, Lee SR, Kim KH, Hong YJ, et al. Carotid artery intima-media thickness in Behcet's disease patients without significant cardiovascular involvement. Korean $\mathrm{J}$ Intern Med 2008;23:87-93.

19. Boulon C, Skopinski S, Constans J. Vein inflammation and ultrasound in Behçet's syndrome. Rheumatology (Oxford) 2016;55:1750.
20. Tong B, Liu X, Xiao J, Su G. Immunopathogenesis of Behcet's Disease. Front Immunol 2019;10:665.

21. Emmi G, Becatti M, Bettiol A, Hatemi G, Prisco D, Fiorillo C. Behçet's Syndrome as a Model of Thrombo-Inflammation: The Role of Neutrophils. Front Immunol 2019;10:1085.

22. Seyahi E, Gjoni M, Durmaz EŞ, Akbaş S, Sut N, Dikici AS, et al. Increased vein wall thickness in Behçet disease. J Vasc Surg Venous Lymphat Disord 2019;7:677-84.e2.

23. Kakehi E, Adachi S, Fukuyasu Y, Hashimoto Y, Yoshida M, Osaka T, et al. Superior Mesenteric Artery Vasculitis in Behçet's Disease: A Case Report and Literature Review. Intern Med 2019;58:127-33.

24. Chandrashekar A, Garry J, Gasparis A, Labropoulos $\mathrm{N}$. Vein wall remodeling in patients with acute deep vein thrombosis and chronic postthrombotic changes. J Thromb Haemost 2017;15:1989-93.

25. Cook CR. Ultrasound Imaging of the Musculoskeletal System. Vet Clin North Am Small Anim Pract 2016;46:355-71.

26. Buzatu C, Duffield S, Chadwick L, Moots RJ. THU0554 the clinical utility of two vasculitis activity scores (BVAS and BDCAF) in Behçet's Syndrome: A prospective cohort study. Annals of the Rheumatic Diseases 2019;78:567. 